information centres. Nevertheless, the onset of recovery was rapid. The important late effect of the poisoning was the development of jejunal ulceration and diverticula formation, and hence the formation of strictures remains a real possibility. The induction of a diuresis seemed to play a particularly important part in preventing acute renal damage.

The prognosis in methylene chloride poisoning then is far from hopeless. With scrupulous intensive care recovery may be anticipated.

We thank Dr H M Leather for permission to report on a patient under his care.

${ }^{1}$ Hughes, J P, fournal of the American Medical Association, 1954, 156, 234.

2 Stewart, R D, American fournal of Nursing, 1967, 67, 85

${ }^{3}$ Dykes, M H M, International Anesthesiology Clinics, 1970, 357.

Freedom Fields Hospital, Plymouth

C J C ROBERTS, MB, MRCP, medical registrar

F P F MARSHALL, MB, BCHIR, senior house officer

\section{Rosacea and migraine}

An association between certain clinical conditions may remain unrecognised for years. There are many ways with which the skin and other systems are linked. Examination of the skin may help the clinician in assessing systemic disease: many patients with dermatitis herpetiformis have intestinal malabsorption and patients with vitiligo show an increase of organ-specific autoimmune diseases. ${ }^{1}$ During our investigation into a new approach to the treatment of facial flushing in rosacea we found three consecutive patients who not only had rosacea but also migraine. This stimulated us to attempt to establish the association between the two conditions.

\section{Methods and results}

One hundred and thirty-seven patients with rosacea and 161 controls were asked whether they had migraine. The control group were predominantly fit hospital personnel; a few had either viral warts, basal cell carcinoma, or gravitational eczema. The definition of migraine was episodic vascular headache with at least two of the following features: unilateral headache; associated nausea or vomiting; visual aura; family history of migraine; and past history of bilious attacks. ${ }^{2}$ The patients with rosacea were mainly women, 89 women and 48 men, aged $20-87$ (mean $46.0 \pm 1.3$ years). The controls were not significantly different: 114 women and 47 men, aged 18-80 (mean $42.0 \pm 3 \cdot 1$ years).

Sixty of the 137 patients with rosacea $(44 \%)$ had suffered from migraine; this contrasted with 21 of the 161 controls $(13.1 \%)$. There was thus a significant association $(P<0.0005)$ between migraine and rosacea (see table). Twenty-nine of the controls had intermittent facial flushing with no other features of rosacea and 16 of these had migraine. Exclusion of these controls further increased the significance of the association between rosacea and migraine.

Incidence of migraine

\begin{tabular}{c|c|c|c}
\hline & Rosacea & Controls & Significance \\
\hline $\begin{array}{c}\text { With migraine } \\
\text { No migraine }\end{array}$ & $60\left(44^{\prime \prime},\right)$ & $21\left(13^{\prime \prime}{ }_{0}\right)$ & $\mathrm{P}<0.0005$ \\
\hline Total & 137 & 140 & \\
\hline
\end{tabular}

\section{Discussion}

We know of no report in which the association between migraine and rosacea has been described. Crawford ${ }^{3}$ reported a 29-year-old woman with migraine who had an unusual eruption and flushing of the right leg, occurring independently of headaches, possibly representing a cutaneous equivalent. Facial migraine-which consists of episodic facial neuralgia, flushing, and reddening of the skin and lachrymation-usually occurs in middle-aged women with a past history of migraine ${ }^{4}$; the presence or absence of rosacea has not been reported in these patients.

The incidence of migraine in our controls is higher than that in other control series. ${ }^{5}$ Thus our observation that $44 \%$ of patients with rosacea suffered from migraine is significant when compared with not only our own but also other control series. The association between rosacea and migraine is not surprising, since both are associated with abnormal vascular reactivity, and both are aggravated by stress. Although migraine tends to occur in younger patients than rosacea, this lack of a temporal relationship does not make the association less likely because it is also seen in other conditions such as eczema and asthma.

The association between rosacea and migraine has several implications. The presence of rosacea may help clinicians in diagnosing migraine variants. Oral contraceptives may significantly increase the frequency and severity of headaches in migrainous women, and hence should patients with rosacea avoid them ? Some patients with migraine develop their attacks after eating cheese or chocolate because of failure to metabolise such compounds as tyramine or phenylethylamine. Do such factors aggravate rosaceous flushing? Study of the facia blood vessels in rosacea may help to understand better the physiological and biochemical abnormalities of the intracranial, extracerebra blood vessels of migraine. Conversely, could drugs prescribed for migraine help facial flushing in rosacea? In low doses clonidine reduces facial flushing and helps migraine at the menopause, and our preliminary investigations show that clonidine probably helps in reducing the facial erythema and flushing of rosacea.

We thank Dr N R Rowell and Dr J A Cotterill for access to patients and Mrs L Lane, Miss S Sharp, and Mrs J Hodson for secretarial help.

${ }^{1}$ Cunliffe, W J, et al, British fournal of Dermatology, 1968, 80, 135.

2 World Federation cf Neurology Research Group on Migraine and Headache in Background to Migraine, p 181. London, Heinemann, 1969.

${ }^{3}$ Crawford, P F, British fournal of Dermatology, 1961, 73, 419.

4 McArdle, J, in Background to Migraine. London, Heinemann, 1969.

${ }^{5}$ Brewis, M, et al, Acta Neurologica Scandinavica, 1966. 42, Suppl 24.

Departments of Dermatology, The General Infirmary, Leeds and $S$ James's (University) Hospital, Leeds

TAN, S G, MB, MRCP, registrar in dermatology

CUNLIFFE, W J, MD, MRCP, consultant dermatologist

\section{Intestinal obstruction complicating orphenadrine treatment}

Gastrointestinal symptoms associated with drugs are common in clinical practice and may take several forms. A reduction in bowel motility with consequent constipation may be caused by drugs with an atropine-like action, including anti-Parkinsonian agents. Parkinsonism itself may cause constipation, ${ }^{1}$ and treatment with a constipation-provoking agent might be expected to produce troublesome symptoms. Severe constipation is perhaps less common than would be predicted but can occasionally be severe enough to cause intestinal obstruction. ${ }^{2}$ A case is presented here in which orphenadrine appears to have precipitated such an event, an association not previously reported.

\section{Case report}

The patient was a 77-year-old man who was diagnosed as suffering from Parkinsonism in 1972, when immobile facies, bradykinesia, and a typical tremor were noted. Orphenadrine was started at a dose of $50 \mathrm{mg}$ three times a day, which improved his symptoms. In 1973 an episode of urinary retention was treated by transurethral resection of the prostate, with complete 
resolution of urinary symptoms. He presented on this occasion with a two-week history of abdominal distension with vomiting for three days. He had the signs of intestinal obstruction but was not acutely ill. Rectal examination showed an empty rectum and a normal prostate. Sigmoidoscopy to $25 \mathrm{~cm}$ was normal but clear bubbly mucus was seen coming from above. Plain $x$-ray examination of the abdomen showed a few fluid levels and barium enema examination suggested carcinoma of the sigmoid colon.

After a defunctioning colostomy a formal laparotomy was performed. Rock-hard faeces were impacted in the sigmoid colon and extended back to the caecum. Manual removal by a colotomy was carried out, after which there was no evidence of carcinoma or any other mural lesion in the colon.

\section{Discussion}

This man had a clinical and radiological syndrome which exactly resembled carcinoma of the colon. The very severe constipation was probably precipitated by orphenadrine. This drug was probably additionally implicated in the patient's previous urinary retention. Most anti-Parkinsonian agents have atropinic properties, and the smooth muscle relaxation so produced leads to bowel stasis.

Warnes et $\mathrm{al}^{2}$ have described six patients in a psychiatric institution who developed intestinal obstruction caused by impacted faeces. All had been taking atropinic anti-Parkinsonian agents as well as their phenothiazine treatment.

Orphenadrine is structurally dissimilar to other anti-Parkinsonian agents and is related to diphenhydramine hydrochloride. ${ }^{3}$ It does, however, have atropinic properties, though fewer than those of benzhexol.4 It thus seems likely that any of the anti-Parkinsonian agents, with the possible exception of amantadine hydrochloride and levodopa, may cause smooth muscle stasis that may be severe. Parkinsonian patients on these drugs should be asked regularly about their bowel habit. An episode of atropinic side effects such as urinary retention should cause consideration of a change of treatment.

We thank Professor S J G Semple and Mr D Ralphs for allowing us to report details of a patient under their care.

1 Simpson, J, in Textbook of Medical Treatment, ed Alstead and Girdwood. London, Churchill, 1974.

2 Warnes, H, Lehmann, H E, Ban, T A, Canadian Medical Association fournal, 1967, 96-112.

3 Esphri, D W, in The Pharmacological Basis of Therapeutics, ed Goodman and Gilman. London, Macmillan, 1970.

4 Friend, D, Clinical Pharmacology and Therapeutics, 1963, 4, 815-22.

Department of Medicine, Middlesex Hospital, London W1N 8AA FETER DAGGETT, MB, MRCP, medical registrar

$S$ Z IBRAHIM, MB, BS, surgical registrar

\section{Metabolic effects of oral salbutamol}

The selective $\beta 2$-adrenergic agonist salbutamol is widely used to relieve airways obstruction. Non-selective $\beta$-adrenergic agonists like isoprenaline stimulate insulin and non-esterified fatty acid (NEFA) release, ${ }^{1}$ but it is uncertain whether these actions are mediated by $\beta 1$ - or $\beta 2$-adrenoceptors. Salbutamol causes insulin release in dogs. ${ }^{2}$ We report here the results of a double-blind, placebo-controlled study of some metabolic effects of oral salbutamol in man.

\section{Methods and results}

Ten healthy non-obese men aged between 18 and 25 years volunteered for study. They reported on each of two mornings 72 hours apart, having fasted for 12 to 16 hours, and lay semi-recumbent during the study. After 30 minutes' rest two basal venous blood samples were withdrawn and a 4-mg tablet of salbutamol or of placebo was given orally, in random order. Further venous samples were withdrawn after 30,60 , and 120 minutes, and each sample was assayed for plasma levels of insulin (immunoassay), glucose (glucose oxidase method), NEFA (measured as palmitic acid with the
Duncombe colorimetric technique), free glycerol and triglyceride (enzymatic method), and potassium (flame photometry).

There was a small but significant sustained increase in plasma insulin after salbutamol, with a more gradual increase in glucose (see table). No such changes occurred after placebo. Plasma NEFA and free glycerol levels increased slowly after both salbutamol and placebo, but the NEFA increase occurred earlier (at 60 minutes) after salbutamol. After salbutamol plasma potassium concentrations decreased progressively from the basal level of $4.1 \pm 0.1 \mathrm{mmol} / 1(4.1 \pm 0.1 \mathrm{mEq} / \mathrm{l})$, but the fall was statistically significant only at the 120 -minute level $(3.9 \pm 0.1 \mathrm{mmol} / 1, \mathrm{P}<0.05)$. Plasma triglyceride levels were unchanged.

Changes in plasma constituents after salbutamol or placebo (mean $\pm S E M$ )

\begin{tabular}{|c|c|c|c|c|c|}
\hline \multicolumn{2}{|c|}{ Plasma constituent } & Mean basal & $30 \mathrm{~min}$ & $60 \mathrm{~min}$ & $120 \mathrm{~min}$ \\
\hline Salbutamol & $\begin{array}{c}\text { Insulin } \\
\text { (mU/1) } \\
\text { Gluccose } \\
\text { (mmol/1) } \\
\text { NEFA } \\
(\mu \mathrm{mol} / \mathrm{l}) \\
\text { Glycerol } \\
(\mu \mathrm{mol} / \mathrm{l})\end{array}$ & $\begin{aligned} 25 & \pm 1 \cdot 6 \\
5 \cdot 3 & \pm 0 \cdot 15 \\
472 & \pm 26 \\
102 & \pm 7 \cdot 6\end{aligned}$ & $\begin{aligned} 36 & \pm 3 \cdot 7^{*} \\
5 \cdot 6 & \pm 0 \cdot 17 \\
497 & \pm 41 \\
100 & \pm 10 \cdot 9\end{aligned}$ & $\begin{array}{c}37 \pm 3 \cdot 0^{*} \\
5 \cdot 9 \pm 0 \cdot 16^{*} \\
633 \pm 51^{*} \\
114 \pm 11.9\end{array}$ & $\begin{aligned} 36 & \pm 4.5 \dagger \\
6.0 & \pm 0.22 \ddagger \\
574 & \pm 51 \\
133 & \pm 10.9 \dagger\end{aligned}$ \\
\hline Placebo & $\begin{array}{c}\text { Insulin } \\
(\mathrm{mU} / 1) \\
\text { Glucose } \\
(\mathrm{mmol} / \mathrm{l}) \\
\mathrm{NEFA} \\
(\mu \mathrm{mol} / \mathrm{l}) \\
\text { Glycerol } \\
(\mu \mathrm{mol} / \mathrm{l})\end{array}$ & $\begin{aligned} 23 & \pm 2 \cdot 7 \\
5 \cdot 2 & \pm 0 \cdot 20 \\
439 & \pm 45 \\
98 & \pm 6 \cdot 5\end{aligned}$ & $\begin{aligned} 23 & \pm 2 \cdot 5 \\
5 \cdot 2 & \pm 0 \cdot 17 \\
470 & \pm 42 \\
91 & \pm 6 \cdot 5\end{aligned}$ & $\begin{aligned} 23 & \pm 2 \cdot 5 \\
5 \cdot 2 & \pm 0 \cdot 17 \\
507 & \pm 62 \\
109 & \pm 9 \cdot 8\end{aligned}$ & $\begin{aligned} 22 & \pm 2 \cdot 1 \\
5 \cdot 3 & \pm 0 \cdot 20 \\
598 & \pm 64 \dagger \\
114 & \pm 8 \cdot 7 \dagger\end{aligned}$ \\
\hline
\end{tabular}

Significant difference from mean basal level $* P<0.01 . \quad+P<0.05 . \quad \$ P<0.001$.

Conversion: SI to traditional units-Glucose: $1 \mathrm{mmol} / 1 \approx 18 \mathrm{mg} / 100 \mathrm{ml}$. NEFA: $1 \mu \mathrm{mol} / 1 \approx 0.26 \mathrm{mg} / \mathrm{l}$. Glycerol: $1 \mu \mathrm{mol} / 1 \approx 0.0092 \mathrm{mg} / 100 \mathrm{ml}$.

\section{Discussion}

Insulin secretion in man is influenced by adrenergic mechanisms, being increased by $\beta$-adrenoceptor stimulation or $\alpha$-adrenoceptor blockade, and decreased by $\alpha$-adrenoceptor stimulation or $\beta$-adrenoceptor blockade. ${ }^{3}$ Whether the pancreatic $\beta$-receptor which mediates insulin release is of $\beta 1$ or $\beta 2$ subtype is not known, nor indeed is it certain that the subtype hypothesis is fully applicable to man.

Our findings agree with those of two studies $^{5}$ of intravenous infusion of salbutamol, which showed appreciable increases in plasma insulin. Nevertheless, the magnitude of the other metabolic changes after intravenous salbutamol seem to differ from those of oral salbutamol. Goldberg et $a^{4}$ found that after intravenous salbutamol the most striking change was an increase in NEFA. The increase in plasma concentration of insulin after salbutamol might be due to direct stimulation of pancreatic $\beta$-receptors, to increased plasma NEFA levels, or to hyperglycaemia. Our finding of a prompt and substantial increase in plasma insulin at a time when changes in NEFA and free glycerol were absent or insignificant suggests that the insulin increase is probably not secondary to a rise in NEFA level. In addition, the more rapid rise in insulin than in glucose seen in this study, together with the fact that intravenous salbutamol in low dosage causes no change in blood sugar but an increase in plasma insulin which is abolished by pretreatment with propranolol, ${ }^{5}$ indicate that salbutamol probably causes insulin release by stimulation of pancreatic $\beta 2$ adrenoceptors.

1 Porte, D, Diabetes, 1967, 16, 150.

2 Loubatieres, A, et al, Diabetologia, 1971, 7, 127.

3 Porte, D, fournal of Clinical Investigation, 1967, 46, 86.

4 Goldberg, R, et al, Postgraduate Medical fournal, 1975, 54, 53.

5 Massara, F, et al, Hormone and Metabolic Research, 1975, 7, 94.

Departments of Medicine and Therapeutics, University of Aberdeen,

Aberdeen AB9 2ZD

$M$ W TAYLOR, BSC, MB, resident house officer

$\mathrm{J}$ GADDIE, MD, medical registrar

L E MURCHISON, PHD, MRCP, lecturer in therapeutics

$\mathrm{K} N \mathrm{~N}$ PALMER, MD, FRCP, reader in medicine 